\title{
Physicochemical Characterization of Pomegranate (Punica Granatum L.) Native to Jordan During Different Maturity Stages: Color Evaluation Using the Cielab and Cielch Systems
}

\author{
Soraya Mercedes Pérez ${ }^{1 *}$ \\ 1 Faculty of Engineering, Natural Resources and Chemical Engineering Department, Tafila Technical \\ University, Tafila P.O. Box 66110, Jordan \\ * Corresponding author's mail: sorayamercedes@yahoo.com
}

\section{ABSTRACT}

Punica granatum L. study is interesting for the functional properties associated to its Phenolic compounds and high volumes of production of this fruit in Jordan. The pomegranate type "pale arils" from Abu Ziyad valley were evaluated during different stages between 20 to 140 days after full bloom, with techniques of chelation, colorimetry and spectrophotometry. The results show that the increasing of sphericity ( 0.79 to 0.91$)$, size diameter (65.58 to $90.41 \mathrm{~mm}$ ), juice yield (46.03 to $55.67 \%$ ), arils mass (31.70 to 61.23\%), TSS total soluble solids (11.01 to 16.80), $\mathrm{pH}$ (2.7 to 3.6) and anthocyanins (7.43 to 12.41 Cyannidine 3 glucoside/100 g) were associated with the decreasing of thickness of the rind (4.9 to $2.77 \mathrm{~mm}$ ), TTA Titrable total acidity (3.5 to 1.1\%), TPC Total phenolics (389.61 to $251.52 \mathrm{mg}$ Gallic acid/100 g), flavonoids (0.73 to $0.40 \mathrm{mg}$ Catechine/g), tannins (8940.11 to $3324.79 \mathrm{ppm}$ ), AA Antioxidant Activity (63.41 to 48.84\%) and Ascorbic acid content (28.91 to $9.48 \mathrm{mg} / 100 \mathrm{~g}$ ); presenting significant differences $\mathrm{p} \geq 0,5$. The paleness of rind and arils is positively related to the anthocyanin content expressed by "a" and "C" color coordinates. The actual investigation demonstrates that high values TSS-pH, low content of tannins and TTA could be successfully indicators of maturity stages rather than the concentration of anthocyanins.
\end{abstract}

Keywords: Anthocyanins, antioxidant capacity, aril juice color, flavonoids, phenols.

\section{INTRODUCTION}

The Abu Ziyad valley forms part of rift valley depression where it has an elevation range between 0 to $100 \mathrm{~m}$ below sea level, presenting an annual average temperature of around $12^{\circ} \mathrm{C}$ and rainfall ranging from 350-300 millimeter (Fig. 1).

The growing scientific interest of pomegranate is due to the functional properties produced for its Phenolic compounds. The term "functional" is understood as the potentially positive effect of a food on health beyond basic nutrition (Pérez, 2014). Pomegranate would represent a potential market due to the rise production in the last production years: 2016, 2017 and 2018 from 12000, 16000 to 21000 tons respectively, with projection to a probable rise (http://moa.gov.jo/ar).
Nowadays the arils, rind, seeds, or mixture of these fractions of the pomegranate (Fig. 2), are used in the treatment of arteriosclerosis and constitute subjects of continuous studies for their possible anti-carcinogenic, anti-microbial and antiviral properties (Shams et al.2011).

Ascorbic acid is one of the compounds of the pomegranate, which acts as antioxidant, and cannot be synthesized by the human body, having to be taken from vegetables and fruits.

$T P C$ are organic compounds with variable molecular structures, which contain at least one phenol group and an aromatic ring linked to a hydroxyl group.

Anthocyanins are water-soluble pigments responsible of the coloration in leaves, flowers and fruits. They are glycosides linked to a sugar by means of a glycosidic bond. 


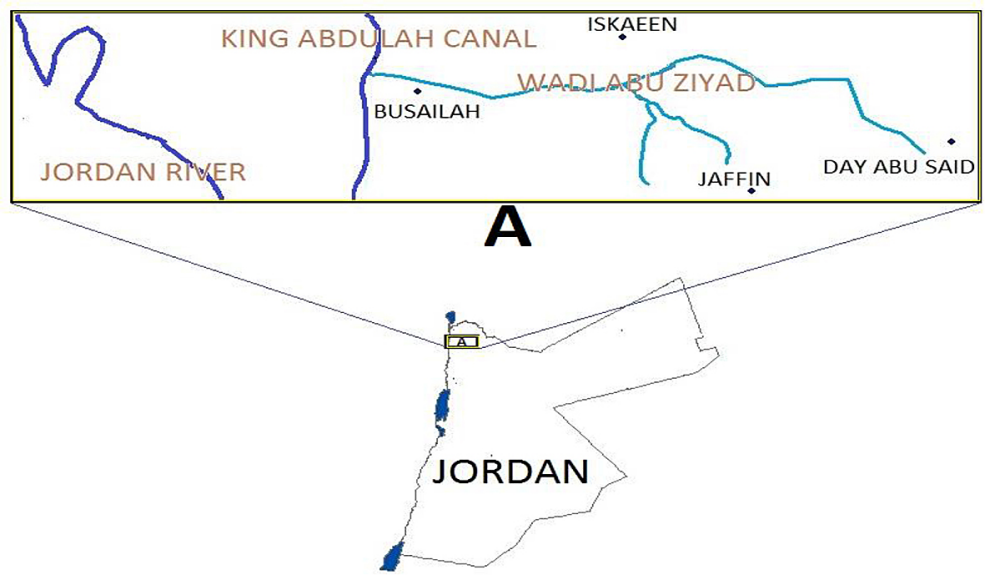

Fig. 1. Location of Abu Ziyad Valley (A) on Jordan map

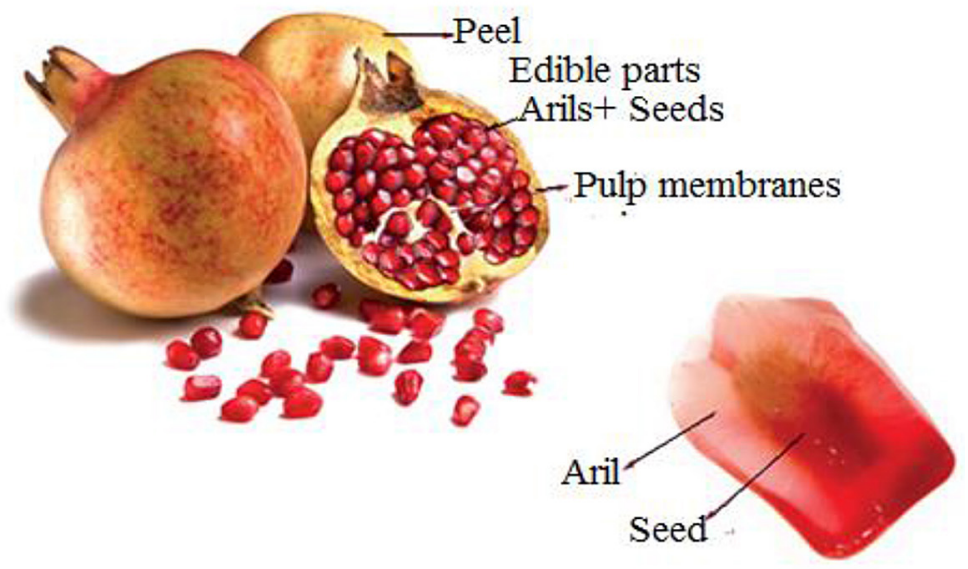

Fig. 2. Parts of Punica Granatum L.

Modified after: https://fsi.colostate.edu/wpcontent/uploads/2014/03/pomegranate_parts_granatum_08.jpg

Condensed Tannins or Proanthocyanidins, are polymeric molecules of flavonoids soluble in water and insoluble in organic solvents, which contains non-nitrogenous structures. They produce a slight degree of astringency, bitterness and characteristic odor in plants acting as defense against herbivores. Flavonoids act as chemical indicators, producing characteristic as flavor, sweetness and aroma to the fruits.

As far as is known, there is no literature available about the characteristics of the pomegranates of the Abu Ziyad valley. Hence, the conducted study is focused on the identification and comparison of the phenolic-chemical and physical parameters across different maturity stages. Furthermore, the color characteristics have not been extensively analyzed in this type of studies, for this reason it is taken into account within the physical parameters.

\section{MATERIALS AND METHODS}

The experimental studies were carried out during the periods of September 2019 to August 2020, in the Departments of Chemical Engineering of the Universities Technical of Tafila-Jordan and Valladolid-Spain.

\section{Physical Characterization}

The selection of the samples was made at random. They were weighed by an electronic $0,001 \mathrm{~g}$ scale (Metler model AE100). The equatorial diameter, latitudinal length and rind thick were determined by Vernier digital precision 0,001 caliper.The moisture content was determined by applying the AOAC method (1980. №20.013). Real density was calculated as the quotient weight and volume. 
Sphericity ( $\varepsilon$ ) was quantified by using the method followed by Pérez (2004). The variables $\boldsymbol{a}, \boldsymbol{b}, \boldsymbol{c}$ are diameters being $\boldsymbol{c}$ the longest diameter and $\varepsilon$ is calculated using the equation:

$$
\varepsilon=(a b c)^{1 / 2} / c
$$

\section{Determination of the color}

The color of the rind samples was measured by means of a Minolta model CR-410 colorimeter (Pro-Cereal Laboratories, Valladolid-Spain). The color was assigned using the Cartesian coordinates $L, a, b$ of the CIELab system. The parameter $a$ moves between green and red of the space color, where $+a$ and $-a$ represent redness and greenness degree respectively. The parameter $b$ moves between blue and yellow where the $-b$ and $+b$ indicate the blueness and yellowness degree, respectively. Luminosity $L$ represents the clarity degree of the sample, which moves between $\mathrm{L}=$ 0 (black, maximum darkness) and $\mathrm{L}=100$ (white, maximum clarity). Chroma" C" describes the percentage of purity $(C=100)$ and the faintness of the color $(\mathrm{C}=0)$. Chroma is calculated using the equation:

$$
C=\left(a^{2}+b^{2}\right)^{1 / 2}
$$

The CIELCh polar system includes the hue angle $h$, which describes the predominant color that an observer perceives, where $0^{\circ}=$ red-purple, $90^{\circ}=$ yellow, $180^{\circ}=$ bluish-green and $270^{\circ}$ blue (McGuire, 1992). Hue angle is calculated by the following equation:

$$
h=\arctan (b / a)
$$

The color of the arils juice was determined by spectrophotometry, using the method provided by Eaton et al. 1995 and Alvarez (2018) for liquid samples.

\section{Statistical analysis}

Three replicates were taken from each sample and the results were used for statistical analysis and reported as mean $\pm \mathrm{SD}$. The regression analysis and Pearson's correlation coefficients were calculated by the SPSS program and values of differences $\mathrm{p}<0.5$ were considered significant.

\section{Chemical characterization}

The samples of arils juice were characterized in the following parameters:

TTA expressed as \% citric acid was measured with the AOAC method 1980 №942.15. It was calculated using the equation (4), where $\boldsymbol{V}_{\mathrm{NaOH}}$ is the base volume (cc) and $\boldsymbol{m}$ the sample mass (g).

$$
\mathrm{TTA}=V_{\mathrm{NaOH}} \cdot N_{\mathrm{NaOH}} \cdot 192.100 /(3 \mathrm{~m} \cdot 1000)
$$

TSS was measured using a ABBE Carl Zeiss refractometer 89553 model and reported as Brix degrees at $25^{\circ} \mathrm{C}$. The maturity index $(M I)$ was calculated by using the equation:

$$
M I=B r i x /(T T A)
$$

Ascorbic acid (vitamin C) content was determined following the AOAC(1980) № 967.21 official method, and reported as mg. Ascorbic acid/100 grams.

TPC was determined by applying the FolinCiocalteu method (Makkar et al. 2000), reporting the results as mg. Gallic acid (GAE)/100g.

The total flavonoids content of the arils extract was quantified using the method proposed by Shams et al. 2011; which is based on the chelation technique with $\mathrm{AlCl}_{3}$. The results are expressed as mg. Catechin /g dry extract.

The concentration of anthocyanins was evaluated quantifying the predominant anthocyanin present, cyanidine 3-glucoside. The official method AOAC (2003), No 2005.02 was followed, expressing the result as mg cyanidine 3-glucoside/100 g.

Condensed tannins were quantified using the Bate-Smith assay (Cáceres et al. 2013). The results were reported as mg.catechin/gram of sample.

Antioxidant capacity was evaluated by means of the method described by Moon and Terao (1988). The absorption at $517 \mathrm{~nm}$ was used to calculate the antioxidant capacity as follows:

$$
\begin{gathered}
\text { Antioxidant Activity }= \\
=\left(1-\left[A_{\text {sample } 517 \mathrm{~nm}} / A_{\text {standard } 517 \mathrm{~nm}}\right]\right) \cdot 100
\end{gathered}
$$




\section{RESULTS AND DISCUSSION}

\section{Physical characterization}

The fruit samples were taken between 20 to 140 days after full bloom. The parameters evaluated are shown in Fig. 3, which presented significant difference $\mathrm{P}<0.05$. At full ripening stage (140 days), the physical analysis recorded maximum values of diameter $\mathrm{D}=90.41 \mathrm{~mm}$; latitudinal length $82.03 \mathrm{~mm}$ and juice yield $55.67 \%$, which revealed an increasing of $39 \%, 41 \%$ and $20 \%$ compared with the measurements at the first maturity stage (Fig. 3A).The results at ripening stage of diameter, latitude length; arils mass and juice yield were $8 \% ; 14 \% ; 6.6 \%$ and $12.14 \%$ higher than the results presented by Zarei et al. 2011 for the "Rabba e Fars" pomegranate at same maturity stage.

The increasing of diameter size, moisture, mass of arils and yield juice along maturity stages, were associated with the reduction of thickness rind across all maturity stages consequence of the ripening of the fruit (Fawole et al. 2011). The values of sphericity reported were closer to one at stages near to full ripening ( $\varepsilon=0.91)$ (Fig. 3A).

The values recorded across all the maturity stages for the thickness of rind and \% seeds, revealed a clear inverse relationship between them (Fig. 3A); corroborated for Pearson's coefficients close to one (Fig. 3B), and were in accordance with Gozlekei et al. (2011) for "Turkish pomegranate".

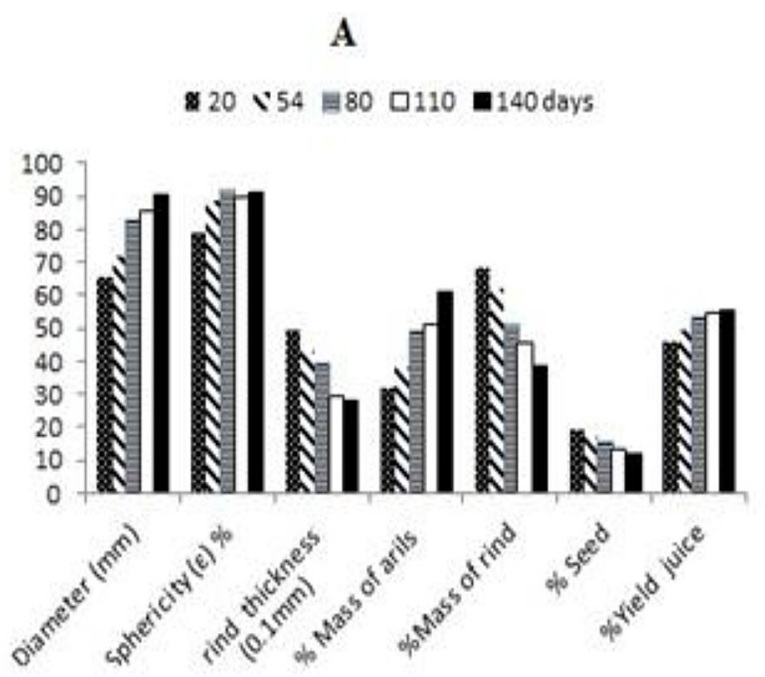

\section{Chemical evaluation}

Some of the main chemical and phenolic parameters evaluated are presented in Figure 4. The increasing TSS values recorded from 11.01 to $16.81^{\circ}$ Brix; denoted a clear increase of sugars level from the unripe to full ripe stage together with $M I$ (from 3.51 to 15.27 ) associated with the maturity process. The maximum TSS and MI reached for the ripe fruit were not associated with the peculiar pale color of arils; MI being exclusively affected by acidity, sweetness and genetic of the fruit.

The $p H$ and TTA are relevant properties for the conservation of the fruits contributing greatly to their stability (Pérez, 2017). The values of TTA and $\mathrm{pH}$ recorded, ranged from $3.5 \%$ to $1.1 \%$ and from 2.7 to 3.6 respectively; revealing continuous decrease during the maturity stages due to change in the content of malic and citric acids (Fig. 4A). The results demonstrate a clear inverse correlation between TTA and $\mathrm{pH}$ in accordance with the work presented by Labbe et al. (2016) for Chilean pomegranates variety "Wonderful", "Chaca" and "Copa".

The TPC results, ranged from 389.61 to $251.54 \mathrm{mg}$ Gallic ac./100g. The ascorbic acid content decreased from 28.9 to $9.48 \mathrm{mg} / 100 \mathrm{~g}$ and the Antioxidant activity (AA) ranged from $63.41 \%$ to 48.845 . The recorded values of ascorbic acid content, TPC and AA showed a tendency to continuously decrease across all maturity stages, leading to deduction of a direct relationship between them similar to the results presented for

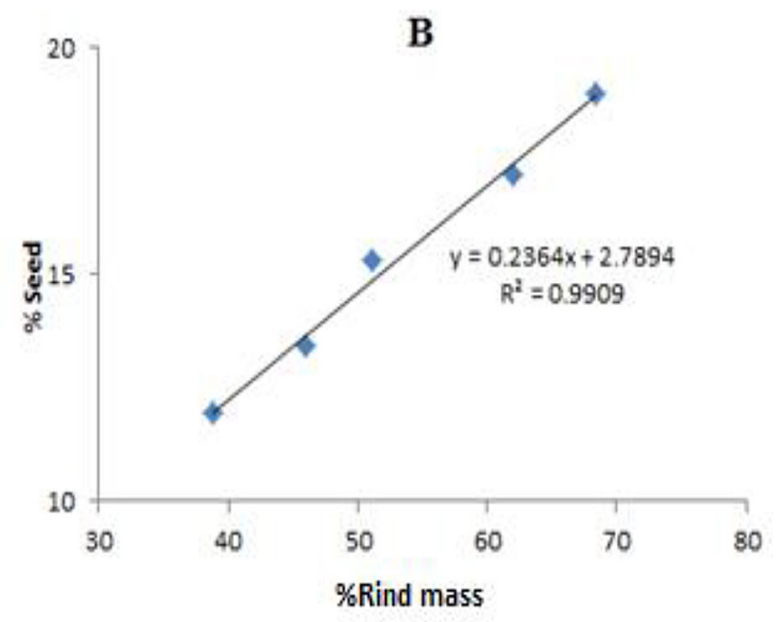

Fig. 3. Evolution of the physical properties (A) and correlation of percentage seed and rind mass (B) 
$\mathbf{A}$

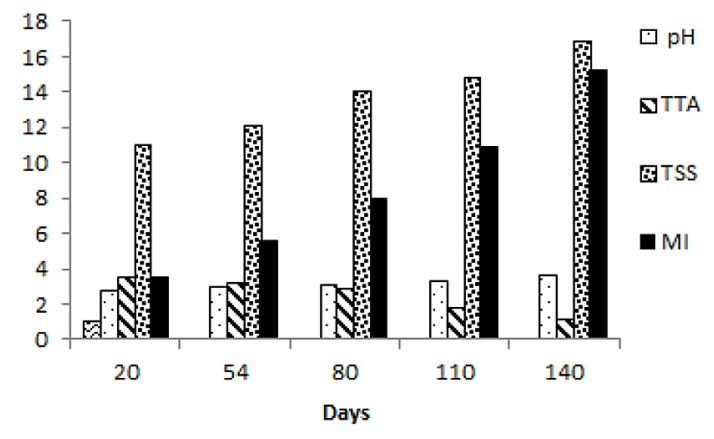

B

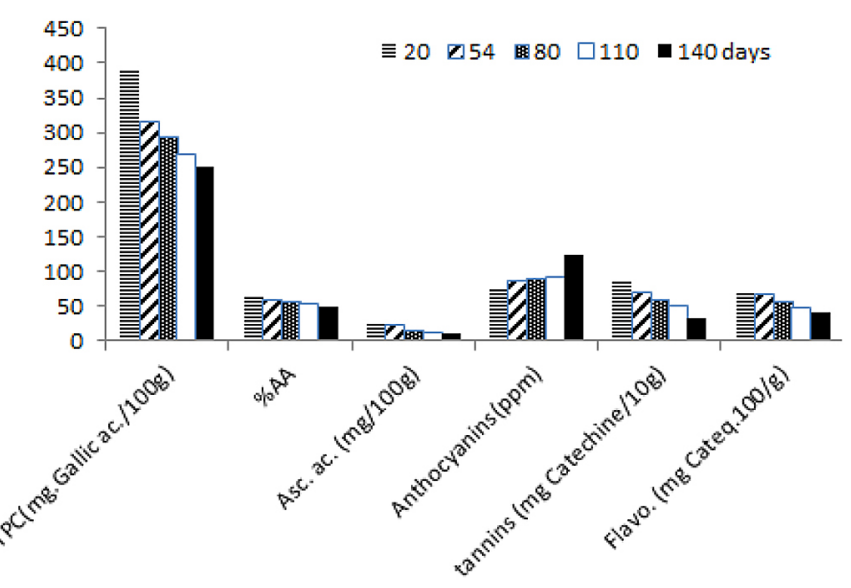

Fig. 4. Change of chemical properties

Gil et al. (2000) and Fisher (2011). Probably, this correlation occurs because of the existence of functional similarities between the Ascorbic acid content, TPC and AA. Ascorbic acid acts as an active antioxidant in oxidation and reduction reactions, associating the content of ascorbic acid to the antioxidant capacity of fruits, stimulating each other, and then creating metabolites that increase the TPC levels (Kulkarniet al. 2005). The decreasing of TPC content with the increasing of MI during maturity stages (Fig. 4 A-B), probably occurs due to the participation of TPC in the biosynthesis mechanism of flavylium anthocyanin ring at maturation stage, with the consequent reduction of TPC levels in concordance with Kulkarni et al. (2005).

The Anthocyanins content recorded the values from 7.43 to $12.41 \mathrm{mg}$ cyannidine3-glucosyde/100g, increasing along maturity stages, which contributes directly to the appearance of color across maturity stages, similar to the studies presented by Radunic et al. (2014).
The paleness of the arils and rind of Abu Ziyad's pomegranate was justified by the low anthocyanins content reached across all maturity stages. The anthocyanins levels at full ripening stage obtained in this study $(12.4111 \mathrm{mg}$. Cyanidin3 -glucoside/100 g), were at range of the values reported by Garcia (2016) for pale pomegranates from "Mollar Elche" - Spain (11 mg. Cyanidin3 -glucoside $/ 100 \mathrm{~g}$ ), and falling within the range specified for Zaouayet al. (2012) for Tunisian pomegranate; from $5 ; 10$ to $49 \mathrm{mg} / 100 \mathrm{ml}$ with an average of $25 \mathrm{mg} / 100 \mathrm{ml}$ (Fig. 5B).

Other varieti.es of pomegranate showed high values of anthocyanins content ranging from 24 to $100 \mathrm{mg}$ Cyannidine-3-glucosyde/100g, such as the case of pomegranates from "Mexico-Queretaro" (Diaz, 2014), "Wonderful" and "Chaca" (Labbeet al. 2016) and "Rabb e Fars" (Zarei et al. 2001), depending mainly of the pomegranate variety (Fig. 5A).

The results of Condensed Tannins and Flavonoids showed an inverse correlation with MI.
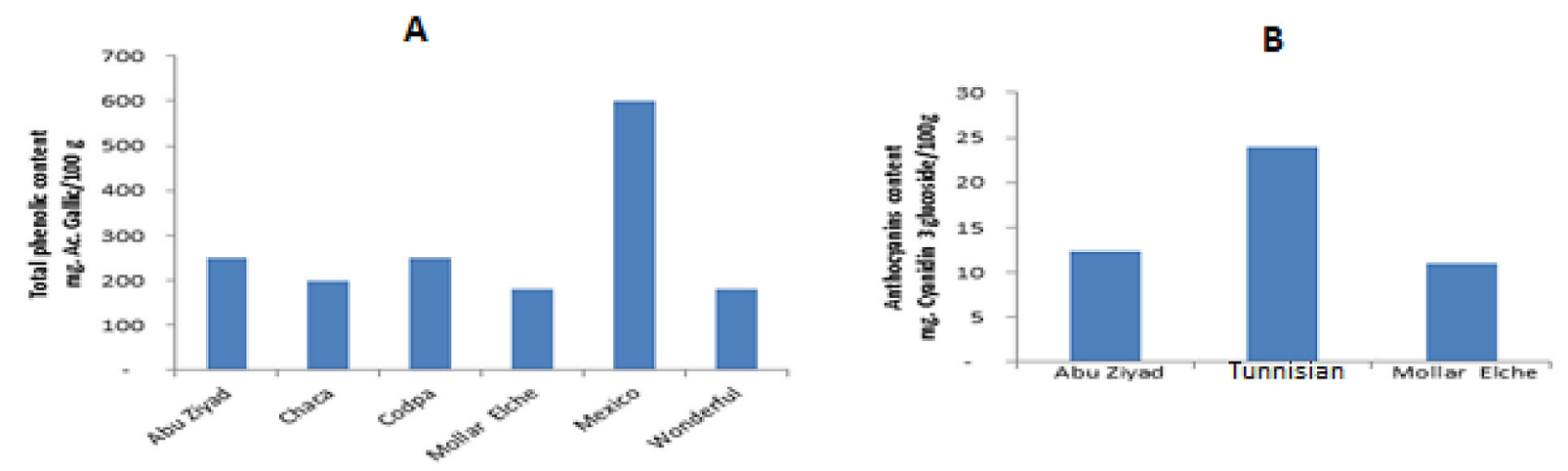

Fig. 5. Anthocyanins and TPC contents for different cultivars of pomegranate at full ripening stage 
Table 1. Results of CIELAB and CIELCH coordinates

\begin{tabular}{|c|c|c|c|c|c|c|c|c|c|c|}
\hline Fraction & \multicolumn{9}{|c|}{ ARILS } & \multicolumn{5}{c|}{ RIND } \\
\hline Days & 20 & 54 & 80 & 110 & 140 & 20 & 54 & 80 & 110 & 140 \\
\hline \multirow{2}{*}{$\mathrm{C}$} & 22,04 & 22,50 & 22,81 & $23,61 \pm$ & 25,01 & 24,61 & 24,02 & 25,03 & 26,60 & 27,30 \\
& $\pm 0,31$ & $\pm 0,13$ & $\pm 0,42$ & 0,31 & $\pm 0,11$ & $\pm 0,21$ & $\pm 0,31$ & $\pm 0,20$ & $\pm 0,19$ & $\pm 0,61$ \\
\hline \multirow{2}{*}{$\mathrm{h}$} & 87,39 & 69,13 & 61,18 & 51,53 & 53,94 & 83,01 & 73,34 & 63,94 & 55,72 & 48,52 \\
& $\pm 1,1$ & $\pm 0,81$ & $\pm 0,54$ & $\pm 0,67$ & $\pm 0,43$ & $\pm 0,35$ & $0,53 \pm$ & $\pm 1,02$ & $\pm 1,51$ & $\pm 1,41$ \\
\hline \multirow{2}{*}{$\mathrm{L}$} & 72,03 & 70,50 & 70,11 & 69,91 & 69,32 & 79,52 & 71,24 & 71,04 & 70,12 & 72,11 \\
& $\pm 0,32$ & $\pm 1,67$ & $\pm 1,45$ & $\pm 0,88$ & $\pm 0,76$ & $\pm 0,67$ & $\pm 0,56$ & $\pm 1,76$ & $\pm 1,65$ & $\pm 1,87$ \\
\hline \multirow{2}{*}{ a } & 1,10 & 8,01 & 11,03 & 14,70 & 17,05 & 3,04 & 7,18 & 11,02 & 15,01 & 18,12 \\
& $\pm 0,13$ & $\pm 0,09$ & $\pm 0,54$ & $\pm 0,67$ & $\pm 0,87$ & $\pm 0,64$ & $\pm 0,46$ & $\pm 0,17$ & $\pm 0,28$ & $\pm 0,34$ \\
\hline \multirow{2}{*}{$\mathrm{b}$} & 22,10 & 21,04 & 20,11 & 18,52 & 19,07 & 24,52 & 23,11 & 22,51 & 22,05 & 20,51 \\
& $\pm 0,71$ & $\pm 0,98$ & $\pm 1,09$ & $\pm 0,76$ & $\pm 0,57$ & $\pm 0,47$ & $\pm 0,53$ & $\pm 0,65$ & $\pm 0,58$ & $\pm 0,71$ \\
\hline
\end{tabular}

* Three replicates for each sample were represented as mean \pm standard deviation.

The Condensed Tannins and Flavonoids content decreased from 8940.1 to $3324.79 \mathrm{ppm}$ and from 0.73 to $0.4 \mathrm{mg}$ Catechine $/ \mathrm{g}$ respectively. The decreasing of the flavonoids content during all maturity stages may be because the flavonoids structure as" (o) condensed tannin" is synthesized as anthocyanins, through an increase in enzymatic activity as anthocyanins synthase (AS) and 3-glycosyl transferase (3GT) until the ripening stage is achieved ( Labbe et al. 2016; Critosto et al.2000).

\section{Analysis of the physical parameter of color}

The results of color coordinates are presented in Table 1, Figure 6 and 7. Analysis of the results of the CIELab Cartesian coordinates for "aril juice» and "rind" during maturity stages, shows that the $+a$ coordinate gradually increased (redness) while the $+b$ and $L$ coordinates decreased and the highest values of $+a$ were achieved at full ripening stage.

The increasing of $+a$ means that the green hue was gradually replaced by the red one. The decreasing of $+b$ indicate that the blue pigments were replaced for the yellow color and the slight fall-off in $L$ values indicated that the brightness has decreased only a little bit during fruit maturation of (Manera et al. 2012). Similar results were observed for the pomegranates variety" cv. Rubi"(Olaniyiet al. 2013) and "Mollar" ascensions (Gil et al. 1995).

The values $C$ and $h$ for arils juice and rind, revealed an inverse relation between them, indicating the quadrant of color diagram and the angle
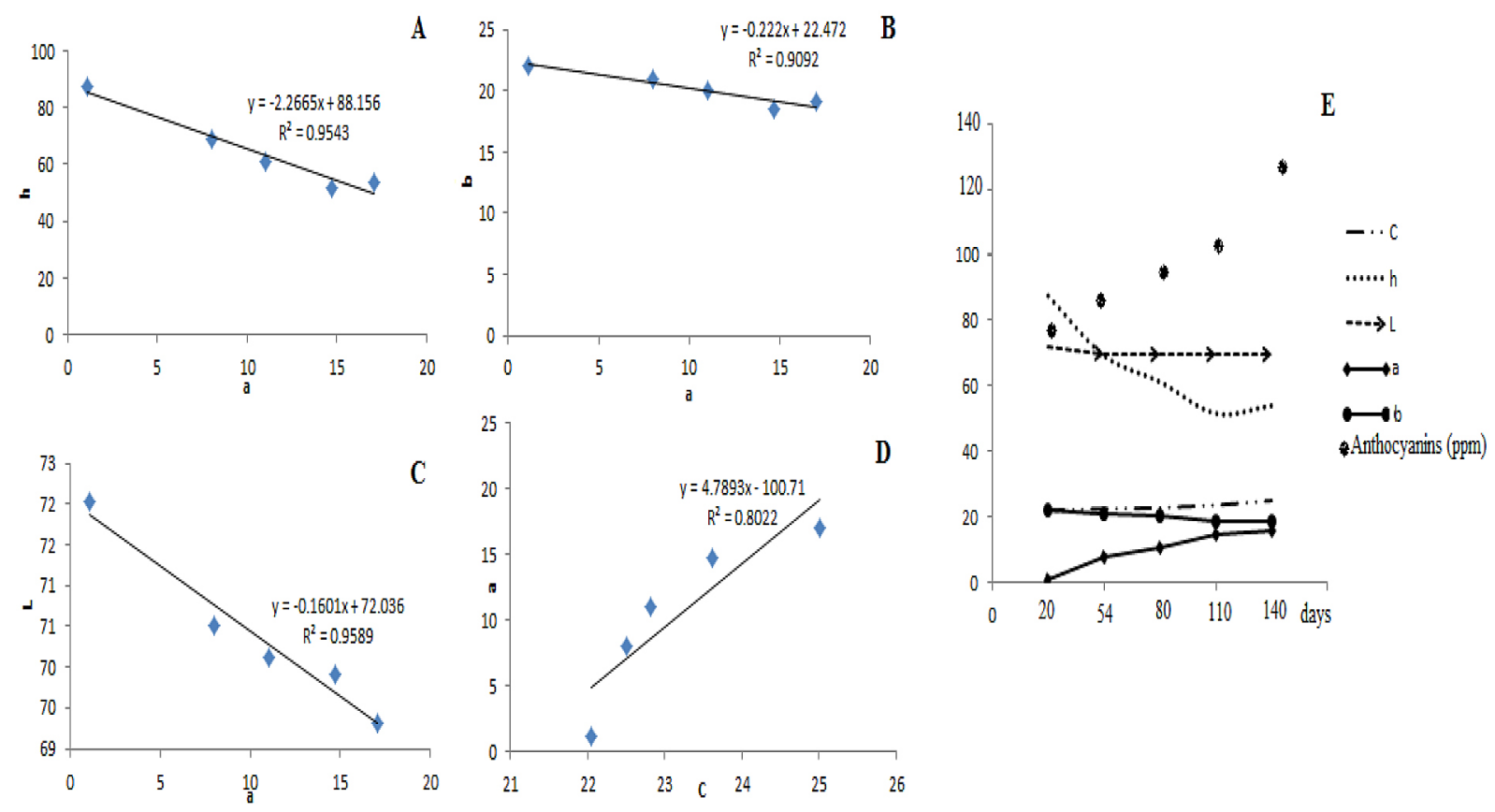

Fig. 6. Correlation between CIELab and CIELCh coordinates and evolution respect to the Anthocyanins content 


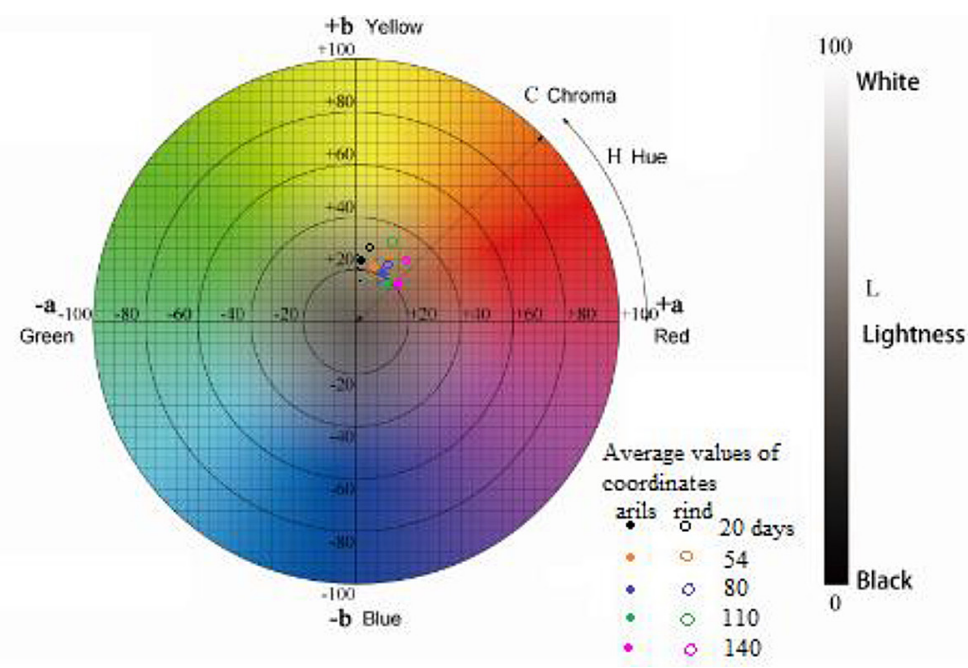

Fig. 7. CIELab and CIELCh coordinates in the color space

with respect to the axis of coordinate $+a$. These results are similar to the discussed for Manera et al. (2012) for pomegranate accession "Mollar de Elche 15". The correlations of the coordinates $a, L, b$ and $C, h$ are demonstrated by the Pearson's coefficients close to one, represented in Figure 6A, B, C, D. The evolution of the coordinates of redness $+a$ and saturation $C$ for aril and rind fraction, would indicate that they are associated with the gradual increasing of the anthocyanins during maturity stages (Fig. 6E), associated for Pearson's correlation factors close to one, shown in the Figure 6D.

\section{CONCLUSIONS}

The high MI, sweetness, low levels of tannin and acidity achieved for Abu Ziyad's pomegranates, make this variety of fruit, suitable for fresh consumption. The "aril paleness", is justified by the low anthocyanin content reached during the maturity stages. The study of physical properties revealed that the thickness of rind across maturity stages showed an inverse correlation with arils mass, percentage of seeds and arils moisture. The inherent color between arils and rinds is due to an interaction between the phenolic- chemical components, exchanged through the porous structure of the arils and rind. Which can be detected by the closeness of "+a", "C" and "b" coordinates of these fractions in the color diagram. Finally this investigation demonstrated that high values TSS$\mathrm{pH}$, low content of TTA, and total tannins could be successfully use as indicators of maturity stages rather than the concentration of anthocyanins.

\section{REFERENCES}

1. Alvarez, A. 2018. [Doctoral dissertation]. Microwave pretreatment for anthocyanin extraction from saffron flowers. Retrieved May 3, 2020 from: http:// uvadoc.uva.es/handle/10324/35064/ .

2. AOAC 2003. No. 2005.02 . Total Monomeric Anthocyanin pigment. Association of Official Analytical Chemistry Official Methods of Analysis. Washington D.C.

3. AOAC 1980. No. 942.15. Acidity titrable of fruit. Association of Official Analytical Chemistry Official Methods of Analysis. Washington D.C.

4. AOAC 1980. No. 967.21. Determination of Ascorbic Acid. Association of Official Analytical Chemistry Official Methods of Analysis. Washington D.C.

5. AOAC 1980. No. 20.013. Determination of moisture content. Association of Official Analytical Chemistry Official Methods of Analysis. Washington D.C.

6. Cáceres-Mella, A., Peña-Neira, A., Narvaez-Bastias, J., Jara-Campos, C., Lopez-Sol, R. and Canales, J. 2013. Comparison of analytical methods for measuring proanthocyanidins in wines and their relationship with perceived astringency. International Journal of Food Science and Technology. 48, 2588-2594.

7. Cristosto, C.H., Mitcham, E.J. and Kader, A.A. 2000. Pomegranate: recommendations for maintaining postharvest quality. Produce. Facts. Postharvest Research and Information Centre, University of California, Davis, USA.

8. Diaz, A., 2014.Calidad nutraceutica de granadas dulce y acida y bioaccesibilidad de sus compuestos fenolicos en un modelo en vivo. [Master dissertation]. Queretaro Autonomus University, Mexico.

9. Eaton, A.D., Clesceri, L.S., Greenberg, A.E. 1995. Association A.W.W. \& Federation. E. Standard 
methods for the examination of water and wastewater / prepared and published jointly by American Public Health Association, American Water Works Association and Water Environment Federation., Washington, DC: American Public Health Association.

10. Fawole, O.A., U.L.Opara, K.I. Theron. 2011. Chemical and phytochemical properties and antioxidant activities of three pomegranate cultivars grown in South Africa.FoodBioprocess.Tech., http://dx.doi. org/10.1007/s11947-011-0533-7/.

11. Fischer, U.A., A.V. Jaksch, R. Carle, and D.R. Kammerer. 2013b. Influence of origin source, different fruit tissue and juice extraction methods on anthocyanin, phenolic acid, hydrolysable tannin and isolariciresinol contents of pomegranate (Punicagranatum L.) fruits and juices. EuropeanFoodResearchTechnology 237, 209-221. doi:10.1007/ s00217-013-1981-2.

12. Garcia, M. 201. Contenido en antocianos y compuestos fenolicos en diferentes frutos frescos y deshidratados. [Doctoral dissertation]. Miguel Hernandez de Elche University, Spain.

13. Gil, M.I., F.A. Tomás-Barberán, B. Hess-Pierce, D.M. Holcroft, and A.A. Kader. 2000. Antioxidant activity of pomegranate juice and its relationship with phenolic composition and processing. Journal of Agricultural and Food Chemistry 48, 4581-4589. doi:10.1021/jf000404a.

14. Gozleke,i S., Saracoglu O., Onursal E. and Özgen M. 2011. Total phenolic distribution of juice, peel and seed extracts of four pomegranate cultivars. Pharmacognos y Magazine 7, 161-164. Doi: 10.44103/0973-1296.80681.

15. Kulkarni, A.P. and Aradhya, S.M. 2005. Chemical changes and antioxidant activity in pomegranate arils during fruit development. Food Chemistry. 93, 319-324. doi:10.1016/j.foodchem.2004.09.029.

16. Labbe, M., Ulloa, P., Lopez, F., Saenz, C., Peña, A. and Salazar, F. 2016. Characterization of chemical compositions and bioactive compounds in juices from pomegranates (Wonderful, Chaca and Codpa) at different maturity stages. Chilean Journal of agricultural research: 76 (4).

17. Makkar, HPS. 2000. Quantification of Tannins in Tree Foliage. A Laboratory Manual for the FAO/ IAEA Coordinated Research Project on 'Use of Nuclear and Related Techniques to Develop Simple Tannin Assay for Predicting and Improving the Safety and Efficiency of Feeding Ruminants on the Tanniniferous Tree Foliage'. Joint FAO/IAEA Division of Nuclear Techniques in Food and Agriculture. Vienna, Austria.

18. Manera, F.J., Legua, P., Melgarejo, P., Martínez, R.,
Martínez, J.J. and Hernández, Fca. 2012. Effect of air temperature on rind colour development in pomegranates. ScientiaHorticulturae. 134, 245-247. doi: 10.1016/j/scienta.2011.11.016.

19. McGuire, RG. 1992. Reporting of objective color measurements. HortScience. 27, 1254-1255.

20. MOA (Jordan Ministry of Agriculture). 2016, 2017, 2018 . Retrieved June 5,2020 from: http://moa.gov. jo/ar-jo/agriinformationar/\%D8\%AA $\% \mathrm{D} 9 \% 82 \% \mathrm{D}$ $8 \%$ A7\%D8\%B1\%D9\%8A\%D8\%B1\%D8\%B3\%D 9\%86\%D9\%88\%D9\%8A\%D8\%A9.aspx/

21. Moon, J.H. and Terao, J. 1988. Antioxidant activity of caffeic acid and dihydrocaffeic acid in lard and human low density lipoprotein. J.Agri.Food Chem. 46: 5062-5065.

22. Olaniyi, A., Fawole, U. and Linus O. 2013. Changes in physical properties, chemical and elemental composition and antioxidant capacity of pomegranate (cv. Ruby) fruit at five maturity stages. ScientiaHorticulturae. 150, 37-46. doi: 10.1016/j/ scienta.2012.10.026.

23. Pérez, S.M. 2004. Aplicación de la deshidratación osmotica para la obtención de rodajas de naranja con procesamiento minimo. [Doctoral dissertation]. Politechnic University of Valencia, Spain.

24. Pérez, S.M. 2014. Functional food that are adjusted to ecuadoriannutrional needs, and optimal technical processing. La Tecnica. Ecuador. 13, 74-81.

25. Pérez, SM. 2017. Processing of passion fruit peel using pressure vacuum osmotic dehydration (PVOD). International Journal for Environment \& Global Climate Change. Jordan. 5(2): 27-30.

26. Radunic, M., Jukic-Spika, M., Goreta-Ban, S., Gadze, J., Diaz-Perez, J.C. and Mc Lean, D. (2015). Physical and chemical properties of pomegranate fruit accessions from Croatia. Food Chemistry . 177: 53-60. Doi:10-1016/j.foodchem.12.102.

27. Shams, M., Hajimahmoodi, M., Reza, M., Sadeghi, N. , Jannat, B., Ranjbar, A., Gholam, N. and Moridi, T. 2011. Comparative antioxidant activity and total flavonoid content of Persian Pomegranate (Punicagranatum L.) cultivars. Iranian Journal Pharmaceutical Research. 10(3): 519-524.

28. Zaouay, F., P. Mena, C.Garcia-Viguera, and M. Mars. 2012. Antioxidant acitivity and physico-chemical properties of Tunisian grown pomegranates (Punicagranatum L.) cultivars. Industrial Crop and Products 40, 81-89.doi: 10.1016/j.indcrop.2012.02.045.

29. Zarei, M., M.Azizi, ,Z.Bashir-Sadr. 2011. Evaluation of physicochemical characteristics of pomegranate (Punicagranatum L.) fruit during ripening. Fruits 66, 121-129. 